\title{
Reconstructing Identities and the Idea of Global Regionalism
}

\author{
Ali Mangera \\ MEng Dip Arch RIBA, Director MYAA \\ AM@myaa.eu
}

We live in a time of great anxiety and change; a time of shifting allegiances where the certainties upon which we have relied have simply vanished. Our once familiar political landscape is in flux; pandemics, civil rights, China, Brexit, Trump, interminable wars and nationalism, have led us to seek answers in ways that are simple and easy to understand. The fingerprints of identity politics are everywhere.

Whilst we come to terms with new 'facts on the ground', we have also come to the realization that our towns and cities are unable to cope with demands we have placed upon them. Urban ghettos, characterless neighborhoods, and gated communities are fertile ground for a Parisian 'gilet jaune' protest. We have through our own actions become complicit in the demise of our cities and the place we call home.

In The Death and Life of Great American Cities (1960) Jane Jacobs illustrates how poor planning led to the marginalization in our cities, dividing communities and creating blight which has now become a common trait in cities around the world. Despite acknowledging our failings, cities have continued to converge into a ubiquitous urbanism where the unique qualities that make cities individual and provide character have been expunged in the name of efficient planning. Our dystopic vision illustrated long before in Charles Booth's 1886 poverty map of London entrenches inequality by partitioning the city into areas varying degrees of affluence and poverty.

Ubiquitous urbanism ultimately leads to greater and greater convergence, which is why retail malls in any city sell the same branded goods behind the same shopfronts to the same demographic. Cities have been emasculated by the needs of global capital and our desire to seek an homogenized and sanitized view of ourselves. But the uniformity that we both seek and impose on the world has also left us disappointed and confused.

Our reaction sometimes calls upon an inner nostalgia; to long for a time when things were simpler. A time when our cities were less structured and less controlled.

An obvious panacea was the postmodern movement which offers the wholesale resurrection of a fictional past omitting the Dickensian squalor for an eager public. And by coincidence or design, the fakery implicit in postmodernism has parallels with fakery we have now come to accept in our political life while the public remain oblivious.

The Prince of Wales's Poundbury estate may be seen as a successful example of an idyllic rural townscape from a bygone era but through its formal gestures, it also reinforces the idea of the British aristocracy complete with its social structures.

The idea of transplanting the past into the present has also given shape to countless real estate projects globally but in the Arabian Gulf this approach describes whole swathes of cities which give rise to branded neighborhoods such as Villaggio in Doha, or Arabian Ranches in Dubai. No longer do we need to visit historic Europe, we now have the means to recreate it on our doorstep. Fake cities in the guise of Venturi- Brown's (1972) Learning from Las Vegas or Hobsbawm's (1983) Invention of Tradition predate our recent obsession with fake news but the Disneyification or more appropriately, Dubaization as Elsheshtawy (2004) describes it continues apace.

Into this backdrop, we have seen valiant attempts to change the dynamic and to provide an alternative, 
which is less Euro-pastiche, and more related to what Frampton (1981) calls Critical Regionalism. Critical regionalism questions the orthodoxy of the 'international style' and its tendency to provide soleless cities lacking identity, yet its approach is intrinsically modern and contrasts with the smoke and mirrors of postmodernism. Critically regional architecture was already present in the modernism of Le Corbusier's Ronchamp and it represents the triumph of contextualism over the dogma of simplified modernist ideology. But Frampton (2018) himself seems to go one step further in 'Beyond Critical Regionalism' claiming that there is a political dimension to regionalism; 'it has a lot to do with local identity, the effort of decision making and the local domain on the territory, which some people are over-concerned about. This is the context in which the theory can still be considered effective today'

Koolhaas's 'Generic City' by contrast claims we are in a progressive stage of losing identity through homogenization where architecture is reduced to functional objects or that "If we simply let cyberspace run its course to a future determined by Silicon Valley, those libertarian-minded engineers will paradoxically lead us to cities shackled by algorithmic conformity. It would be a neural network, yes, but one that operates in lock step."

MYAA's approach to architecture can in many ways be considered as critically regional but not in the way Frampton sees it. Our view mediates a space between the fait accompli of the global city and the need for regional architecture; perhaps a new kind of 'global-regionalism'. To achieve this we use all modes of production from socio-cultural analysis, big data and parametrics through to buildings made by hand. We are of course aware that the proliferation of global culture and ideology creates winners and losers, but its presence for good or for bad is inescapable.

The question we must also ask is 'what is regional?' when the idea of region in both space and time are fluid. Is 'regional architecture' pre-colonial or represented by the bounds of a Nation State and if so, which period should we consider? Is Geoffrey Bawa's work in Ceylon 'regional' and should a European man be empowered to decide what is regional architecture for Sri Lanka. And in the case of The Arabian Gulf, should regional architecture be inspired by The Nabateans of the Levant or the Ottomans, Persians, or Bedouins and what is the limit of our territory?

The needs of global capital has given rise to global culture which in turn has led architecture to converge around ideas that are generic and risk averse. In contrast, the architecture of global regionalism cannot be seen simply in a formal sense but rather as ideas that question accepted notions of territory and region, or how buildings come into being, how they are used programmatically and how they adapt to meet the challenges of their unique socio-cultural context.

Where the 'international style' bluntly impose solutions upon the city and where postmodernism reduces the city to a caricature, global regionalism must be provocative, sensitive to context whilst remaining conscious of patronage.

We recognize also that architecture can never escape its political purpose; from the Great Pyramid of Giza to Mussolini's Palazzo della Civiltà Italiana; or China TV's polished headquarters, all buildings regardless of scale are a manifestation and projection of our beliefs and our anxieties.

Using tools that are available to us, MYAA attempts to create architecture through cultural layering, whilst we question the orthodoxy of existing building typologies . In so doing, we do not subscribe to the singularity of context; it is both necessary and important to create the context into which architecture resides if only to pose questions and to facilitate new forms of spatial organization. We are aware also of our limitations; namely our ability to convince developers and governments to invest in ideas that challenge the status quo.

By way of example, MYAA's Faculty of Islamic Studies on the Education City campus revisits theological pedagogy and creates a new dynamic between learning and praying space. Based on a spiral 
plan, the scheme suggests an interchangeability between gaining knowledge (academic space) and seeking enlightenment (praying space). In terms of form, outwardly and by way of gesture, the scheme presents Islam as a faith that both embraces and projects contemporary society. But its form is also related to climatic conditions which led us to carve out cooler shaded areas that create microclimates whilst also inviting visitors from the campus through pathways that facilitate contemplation.

The building is layered with meaning and interpretation; its shaded undercroft is created by the five pillars of Islam that elevate the prayer space above. Qur'anic verse is applied to the buildings fabric so that the building can literally and metaphorically be 'read'. The landscaping incorporates a fourpart Islamic garden with rivers of paradise defined by scripture. Our approach provides a basis for exploration and discovery rather than giving simple answers to complex questions of faith.

In London, we are currently working on a Cultural Centre in Harrow; a multifaith community building funded by East African Asian migrants that have settled in the UK. The story of the ancestral journey of the client from Persia to India, then to East Africa and eventually to the UK is described through an ornate patterning on the skin of the building. But the idea of patterning is not whimsical. The site is located in the heart of what John Betjeman calls Metro Land, an area that was influenced by the work of William Morris and the Arts and Crafts movement. Morris was by coincidence greatly influenced by Islamic geometric patterning and his work can be seen as a synthesis of both local and global in the arts and crafts tradition.

Our horticultural school in Rabat is built on a former municipal dumpsite on the outskirts of the city. The dumpsite contaminated the local watercourse and blighted neighboring communities whilst also emitting large quantities of landfill gas. The municipality introduced a biogas capture facility; the first of its kind in Africa, capturing 250,000 tons of landfill gas and providing energy for 5000 homes whilst reducing greenhouse gases. The low budget building is clad in hand-made clay bricks use traditional construction techniques. The scheme is certainly not an iconic building, but it does connect with context through its materiality and its community engagement. And its earth walling ensures the school remains cool over the Rabat's hot summer months

In Madagascar we worked on an Academy and a Galleria building which are inspired by the Malagasy tradition of pointed roofs. The building's metallic skin also incorporates a pattern from the Malagasy Fanorona board game in the spirit of the local Zafimaniry wood craft tradition

And in Barcelona we are about to start work on the city's iconic cathedral; a building that is symbolic not only in terms of architecture but also in terms of its significance to Catalan independence. As Frampton suggests 'In Spain, there is a request for direct democracy. So I think there is an aspect of Critical Regionalism which has a kind of political dimension, it has a lot to do with local identity, the effort of decision making and the local domain on the territory, which some people are over-concerned about.

It is too early to say how our work in Barcelona will materialize but what is clear is that the project will harness new and emerging technologies that will be co-opted to address the needs of both a global and regional audience.

\section{References}

Beyond Critical Regionalism with Kenneth Frampton (2018). Dedalo building Lab. Retrieved from www. dedalobuildinglab.com/architecture-conversations/beyond-critical-regionalism-a-conversation-with-kennethframpton/.

Elsheshtawy, Yasser (2004). Dubaization. Retrieved from https://dubaization.com/dubaization. 
Frampton, Kenneth (1981). Critical Regionalism.

Hobsbawm, Eric (1983). Invention of Tradition.

Jacobs, Jane (1961). Death and Life of Great American Cities.

Koolhass, Rem (n.d.) Interview with Washington Post on 09.07.2018 and The Generic City on 1995

Venturi, R., \& Brown, D. S (1972). Learning from Las Vegas.

Wikipedia (n.d.). Fanorona. Retrieved from https://en.wikipedia.org/wiki/Fanorona.

Wikipedia (n.d.). John Betjeman calls Metro Land. Retrieved from https://en.wikipedia.org/wiki/Metro-Land_(1973_ film).

Wikipedia (n.d.). Poundbury. Retrieved from https://en.wikipedia.org/wiki/Poundbury.

Cite this article as: Mangera A., "Reconstructing identities and the idea of Global Regionalism", International Conference on the $4^{\text {th }}$ Game Set and Match (GSM4Q-2019), Doha, Qatar, 6-7 February 2019, https://doi. $\operatorname{org} / 10.29117 /$ gsm4q.2019.0021 